Chapman University

Chapman University Digital Commons

Pharmaceutical Sciences (MS) Theses

Dissertations and Theses

Spring 5-2020

\title{
Role of Protein Phosphatase-2A in Regulating Monocyte Activation by Soluble and Crystalline Uric Acid in Gout
}

\author{
Sandy ElSayed \\ Chapman University, selsayed@chapman.edu
}

Follow this and additional works at: https://digitalcommons.chapman.edu/

pharmaceutical_sciences_theses

Part of the Other Pharmacy and Pharmaceutical Sciences Commons

\section{Recommended Citation}

ElSayed, S. Role of Protein Phosphatase-2A in Regulating Monocyte Activation by Soluble and Crystalline Uric Acid in Gout. [master's thesis]. Irvine, CA: Chapman University; https://doi.org/10.36837/

chapman.000150

This Thesis is brought to you for free and open access by the Dissertations and Theses at Chapman University Digital Commons. It has been accepted for inclusion in Pharmaceutical Sciences (MS) Theses by an authorized administrator of Chapman University Digital Commons. For more information, please contact laughtin@chapman.edu. 


\title{
Role of Protein Phosphatase-2A in Regulating Monocyte Activation by Soluble and Crystalline Uric Acid in Gout
}

\author{
A Thesis by \\ Sandy ElSayed \\ Chapman University \\ Irvine, CA \\ Chapman University School of Pharmacy \\ Submitted in partial fulfillment of the requirements for the degree of \\ Master of Science in Pharmaceutical Sciences
}

May 2020

Committee in charge:

Khaled A. Elsaid, Pharm.D., Ph.D., Chair

Surya Nauli, Ph.D.

Miao Zhang, Ph.D.

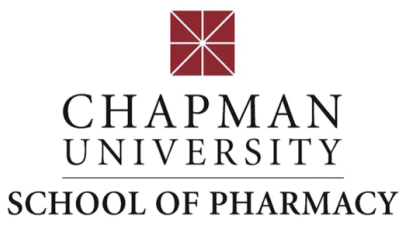


The thesis of Sandy ElSayed is approved.

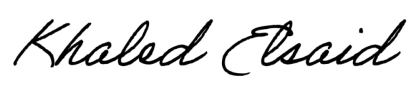

Khaled A. Elsaid, Pharm.D., Ph.D., Chair

Surya Nauli

Surya Nauli, Ph.D.

Miao Zhang

Miao Zhang, Ph.D.

May 2020 
Role of Protein Phosphatase-2A in Regulating Monocyte Activation by

Soluble and Crystalline Uric Acid in Gout

Copyright (C) 2020

by Sandy ElSayed 


\section{ACKNOWLEDGEMENTS}

First and foremost, I would like to express my deep and sincere gratitude to my advisor Dr. Khaled Elsaid for the continuous support and invaluable guidance. His motivation, enthusiasm and sincerity have deeply inspired me. His immense knowledge and constant support helped me in my research journey and in writing this thesis. I could not have imagined having a better advisor for my master's degree.

I would also like to thank my thesis committee Dr. Surya Nauli and Dr. Miao Zhang for their distinguished skills, insightful comments and sharing their diverse ideas in from their own fields of research.

I wish to express my deepest gratitude to Marwa Qadri for providing her love, care and shelter, sharing her knowledge generously and helping in experiments, analysis of data as a teacher and providing words of reassurance during tough times as a friend.

I am eternally grateful to my father, Mohamed Talaat, who never missed out on a chance to push me forward in life and for being my best friend, teacher and role model. I would like to thank my mother for her heart-warming kindness and sense of humor. My brother, Abdulla, for his unconditional love, patience and bearing with me at the beginning of this journey.

Finally, I would like to thank my friends, Marwa for her being the older sister who raised me up every time I got weary, Sama, Gelan and Samira, for their emotional support and for keeping in touch with me despite the long distance. 


\section{ABSTRACT \\ Role of Protein Phosphatase-2A in Regulating Monocyte Activation by Soluble and Crystalline Uric Acid in Gout}

by Sandy ElSayed

Gout is a chronic inflammatory disease caused by the phagocytosis of monosodium urate monohydrate (MSU) crystals by monocytes/macrophages resulting in downstream expression and production of interleukin-1 beta (IL-1 $\beta$ ) and chemokines. The activation of monocytes by MSU crystals involves the priming of monocytes with danger signals e.g. lipopolysaccharide (LPS) or soluble uric acid (UA), crystal phagocytosis and subsequent NLRP3 inflammasome activation and conversion of pro-IL-1 $\beta$ to active IL-1 $\beta$. Protein-phosphatase-2A (PP2A) is a serine/threonine phosphatase that plays an important role in cell growth and inflammation. The prodrug Fingolimod (FTY720) and its phosphorylated active metabolite (p-FTY720) activate intracellular PP2A. We hypothesized that monocyte activation by MSU crystals is mediated by a reduction in intracellular PP2A activity and restoring PP2A activity reduces MSU-induced inflammation in monocytes. We aimed to investigate the role of PP2A in regulating monocyte priming and activation by MSU crystals and evaluate whether intracellular PP2A activation exerts an anti-inflammatory effect in MSU-stimulated monocytes.

Human THP-1 monocytes were primed with a combination of UA and LPS. MSU stimulation was performed for 4-6 hours and MSU crystal phagocytosis, PP2A activity, IL-1 $\beta$ expression and production were studied in primed and unprimed monocytes. We performed PP2A knockdown in THP-1 monocytes and evaluated the impact of PP2A attenuation on IL-1 $\beta$ 
expression and production in unprimed THP-1 monocytes. Time-dependent intracellular PP2A activation in response to FTY720 or p-FTY720 treatments was studied and we evaluated the impact of p-FTY720 treatment on IL-1 $\beta$ expression and production in MSU stimulated human monocytes.

Priming with UA+LPS increased MSU phagocytosis and IL-1 $\beta$ expression and production in monocytes. This effect was associated with a reduction in intracellular PP2A activity. PP2A knockdown increased IL-1 $\beta$ expression and production. FTY720 and p-FTY720 increased intracellular PP2A activity in monocytes. p-FTY720 treatment reduced IL-1 $\beta$ expression and production in UA+LPS pre-treated monocytes following MSU stimulation mediated by an increase in PP2A activity with no alteration in PP2A gene expression.

In summary, UA and LPS enhanced MSU phagocytosis, expression and production of IL-1 $\beta$ via a reduction in PP2A activity. Pharmacological restoration of PP2A activity exerted an antiinflammatory effect. We conclude that PP2A is a novel therapeutic target for gout treatment. 


\section{TABLE OF CONTENTS}

$\begin{array}{lr}\text { 1. Introduction } & 1\end{array}$

1.1 Background and significance $\quad 1$

1.2 Gout pathogenesis is a multi-step process initiated by tissue-resident macrophages 3

1.3 The proinflammatory mechanism of soluble uric acid 8

1.4 Protein phosphatase-2A (PP2A) plays a key role in regulating intracellular inflammatory signaling pathways 9

1.5 Clinically-available PP2A activators show efficacy in models of inflammation 11

$\begin{array}{lr}\text { 2. Hypothesis } & 12\end{array}$

$\begin{array}{lll}2.1 & \text { Aim } 1 & 12\end{array}$

$2.2 \operatorname{Aim} 2 \quad 12$

$\begin{array}{lr}\text { 3. Materials and Methods } & 13\end{array}$

$3.1 \quad$ Reagents

3.2 Phagocytosis of FITC labeled fluorescent beads in primed monocytes

3.3 Phagocytosis of MSU crystals by primed monocytes

3.4 IL-1 3 gene expression in primed monocytes

3.5 IL-1 13 production by primed THP-1 monocytes

3.6 PP2A knockdown using protein phosphatase-2A catalytic subunit (PP2Ac)

3.7 IL-1 $\beta$ expression and production in PP2Ac siRNA-treated THP-1 monocytes following incubation with MSU crystals

3.8 Impact of FTY720 and FTY720-P treatments on intracellular PP2A activity in human THP-1 monocytes

3.9 Impact of FTY720-P treatment on $I L-1 \beta$ and PP $2 A$ expression and $I L-1 \beta$ production in MSU-treated primed THP-1 macrophages 
4. Results

4.1 Impact of UA+LPS priming on phagocytosis of fluorescent beads and MSU crystals by THP-1 monocytes

4.2 Impact of UA + LPS priming on intracellular PP2A activity, IL-1 $\beta$ expression

4.3 PP2A knockdown using PP2A siRNA and effect of knockdown on IL-1beta expression and production

4.4 PP2A activation by FTY720 and FTY720-P at different time-points and FTY720-P enhancement of PP2A activity of primed monocytes

4.5 Impact of FTY720-P on cell viability, PP2A expression, $I L-1 \beta$ expression and production in human THP-1 monocytes

5. Discussion

6. Conclusion

7. References 


\section{LIST OF TABLES}

Table 1 Primers for gene amplification 


\section{LIST OF FIGURES}

Figure $1 \quad$ Structure of toll-like receptors (TLRs) 4

Figure 2 Toll-like Receptor (TLR) Signaling Pathway 5

Figure 3 Production of IL- $\beta$ following NLRP3 Activation in response to monosodium urate crystal challenge

Figure $4 \quad$ Interleukin-1 beta $(I L-1 \beta)$ signaling pathway $\quad 8$

Figure 5 Regulation of protein phosphatase-2A (PP2A) and its associated signaling pathways

Figure 6 Phosphorylation of Fingolimod (FTY720) to Fingolimod phosphate (FTY720-P)

Figure 7 Activation of protein-phosphatse-2A by fingolimod (FTY720)

Figure 8 Impact of soluble uric acid and lipopolysaccharide priming on phagocytosis of FIT-C labeled beads by THP-1 monocytes

Figure 9 Impact of soluble uric acid and lipopolysaccharide priming on phagocytosis of monosodium urate (MSU) crystals by THP-1 monocytes

Figure 10 Impact of uric acid (UA) and lipopolysaccharide (LPS) priming on protein phoaphstase-2A (PP2A) activity, interleukin-1 beta (IL-1 $)$ expression and production in THP-1 monocytes

Figure 11 Impact of protein phosphatase-2A (PP2A) silencing on monosodium urate monohydrate (MSU) crystal -induced interleukin-1 beta (IL-1 $\beta)$ expression and production by human THP-1 monocytes

Figure 12 Impact of fingolimod prodrug (FTY720) and active phosphate metabolite (FTY720-P) treatments on intracellular protein phosphatase-2A (PP2A) activity in THP-1 monocytes

Figure 13 Impact of fingolimod phosphate (FTY720-P) treatment on THP-1 monocyte viability, expression of $P P 2 A c, I L-1 \beta$ expression and production in $U A+$ $L P S$ primed and MSU stimulated monocytes 


\section{LIST OF ABBREVIATIONS}

\section{$\underline{\text { Abbreviation Meaning }}$}

ARDS Acute Respiratory Distress Syndrome

ASC Apoptosis-associated speck-like protein containing a caspase recruitment domain

ATP Adenosine triphosphate

COX Cyclooxygenase

CYP3A4 Cytochrome P3A4

DAMPs Damage associated molecular patterns

IKK I $\quad$ I B Kinase

IL-1R1 Interleukin 1 receptor type 1

IL-1RAP IL-1 receptor accessory protein

IRAK IL-1R associated kinase protein

LPS Lipopolysaccharide

MAPK Mitogen-activated protein kinase

MCP-1 Monocyte chemoattractant protein 1 


\begin{tabular}{|c|c|}
\hline MSU & Monosodium urate crystals \\
\hline MyD88 & Myeloid differentiation 88 \\
\hline NADP & Nicotinamide adenine dinucleotide phosphate \\
\hline$N F-\kappa B$ & Nuclear factor kappa-light-chain-enhancer of activated B cells \\
\hline NLRP3 & Nucleotide-binding domain (NOD)-like receptor protein 3 \\
\hline NSAIDs & Non-steroidal anti-inflammatory drugs \\
\hline PAMPs & Pathogen associated molecular patterns \\
\hline PP1 & Protein phosphatase 1 \\
\hline PP2A & Protein phosphatase $2 \mathrm{~A}$ \\
\hline PPRs & Pattern recognition receptors \\
\hline PSPs & Phosphoprotein phosphatase \\
\hline ROS & Reactive oxygen species \\
\hline S1P & Sphingosine-1-phosphate \\
\hline TAK & TGF- $\beta$-activated kinase \\
\hline TGF- $\beta$ & Transforming growth factor $\beta$ \\
\hline $\mathrm{T}$ & Toll/interleukin receptor \\
\hline
\end{tabular}


TLRs Toll-like receptor

TNF- $\alpha \quad$ Tumor necrosis factor $\alpha$

TOLLIP Toll-interacting protein

TRAF6 TNF- $\alpha$ receptor-associated factor 6 


\section{Introduction}

\subsection{Background and significance}

Gout is a prevalent inflammatory arthritis that affects the articular joints (mainly the metatarsophalangeal and knee joints) owing to the deposition of insoluble uric acid crystals in soft tissues causing pain and inflammation (1). In the early history of medical writing, it appeared in the medical records and constituted a challenge to physicians. Management of gout symptoms has improved with the availability of anti-inflammatory agents and urate lowering therapy, but a significant proportion of gout patients still have suboptimal outcomes (2). The overall prevalence of gout in general population is $1-4 \%$ and it is more common in men (3-6\%) than women (1-2\%). In populations above 80 years old, the prevalence rises to $10 \%$ in men and $6 \%$ in woman. Gout affects 2.68 in 1,000 persons annually (3). The incidence of gout is constantly increasing worldwide and about $3-10 \%$ of gout patients are not adequately managed causing treatment failure gout (refractory gout) which can't be controlled by conventional therapies $(4,5)$.

The hallmark of gout is the precipitation of monosodium urate monohydrate (MSU) crystals contributed to by an increase in serum uric acid levels (1). Gout flares are characterized by self-limiting acute inflammation that lasts 2-3 days (6) interspersed between the low-grade inflammatory condition that is chronic gout (7). Hyperuricemia is defined as a uric acid blood level above $6.5 \mathrm{mg} / \mathrm{dL}$. While hyperuricemia is a risk factor for gout, the relationship between hyperuricemia and gout is more complex. Many individuals have hyperuricemia 
without gout or even formation of urate crystals while approximately $5 \%$ of patients with hyperuricemia (serum uric acid above $9 \mathrm{mg} / \mathrm{dL}$ ) advance to gout (8).

Current acute gout treatment modalities include colchicine, corticosteroids and non-steroidal anti-inflammatory drugs (NSAIDs). Colchicine prevents the activation of macrophages and subsequently the NLRP3 inflammasome. It also inhibits the production of chemotactic factors, MCP-1 and IL-8. However, the onset of colchicine's clinical effect is slow and is associated with significant toxicities which limits its use in acute flares of gout $(9,10)$. The most common side effects of colchicine are gastrointestinal symptoms such as diarrhea reported in $23-77 \%$ of patients. Aplastic anemia has also been associated with exposure to colchicine. The elderly and patients with renal or hepatic dysfunctions are at increased risk of developing these toxicities. Colchicine has clinically significant drug-drug interactions with CYP3A4 inhibitors such as erythromycin. NSAIDs are used in acute gout flares owing to their inhibition of cyclooxygenase-2 (COX-2) and downstream production of prostaglandins. However, they have a number of side effects. Gastrointestinal side effects could be minor as dyspepsia or severe as ulcers and perforations occurring in about $10 \%$ of patients. They also reduced kidney function in $1-5 \%$ of patients. They are associated with increased risk of cardiac events especially in patients with cardiovascular diseases. Other treatments include corticosteroids, which cause dysphoria, mood disorders, hyperglycemia, immune suppression and fluid retention. This makes the treatment of acute gout in patients with diabetes and hypertension with glucocorticoids challenging (11). The use of biologics like IL-1 $\beta$ receptor antagonist is still being evaluated. Notably, none of the current 
treatments provide a gout cure. Therefore, optimal gout management remains as an unmet clinical need.

\subsection{Gout pathogenesis is a multi-step process initiated by tissue-resident macrophages.}

In synovial joints, the synovial membrane is composed of two layers; the first layer is thin and highly cellular containing synovial macrophages and synovial fibroblasts. Synovial fibroblasts produce hyaluronic acid and lubricin to establish an extracellular matrix to support the synovium. Macrophages are low in number in healthy synovial joints. When hyperuricemia leads to precipitation of MSU crystals in joints, MSU crystals are phagocytosed by macrophages resulting in the production of proinflammatory cytokines, which enhances synovial recruitment of additional immune cells leading to inflammation (12). The effect of precipitated MSU crystals on the macrophages composes the first trigger of the inflammasome. The cellular recognition of MSU crystals occurs through toll-like receptors (TLRs), especially TLR2 and TLR4 (13). This leads to the production and secretion of pro-inflammatory cytokine, interleukin-1 beta (IL-1 $\beta$ ), which recruits more inflammatory cells and amplifies the inflammatory response (14). MSU crystals mediate their effect after being phagocytosed by stimulation of nicotinamide adenine dinucleotide phosphate (NADP) oxidase leading to the generation of reactive oxygen species (ROS) and activation of nucleotide-binding domain (NOD)-like receptor protein 3 (NLRP3) inflammasome (15).

The innate immune system produces an initial rapid inflammatory response in response to invading pathogens. This occurs when innate immune receptors recognize pathogen-related products as an antigen in order to subsequently eliminate those pathogens through their 
engulfment or production of inflammatory cytokines. Innate immune receptors are also known as pattern recognition receptors (PRRs) and they are present on cell surface and in cytoplasm. Toll-like receptors (TLRs) are an important group of PRRs. TLRs are located on immune cells surfaces and play an essential role in mediating the host's defense against pathogens. In humans, TLRs are activated by different Pathogen-Associated Molecular Patterns (PAMPs) including lipopolysaccharide as is the case with TLR4 and lipopeptide (Pam3CSK4) as is the case with TLR2. TLRs are integral membrane receptors (type 1) with an $\boldsymbol{N}$-terminal ligand recognition exterior domain, one transmembrane helix and a $\boldsymbol{C}$-terminal cytoplasmic signaling domain also known as toll/interleukin receptor domain figure 1(16).

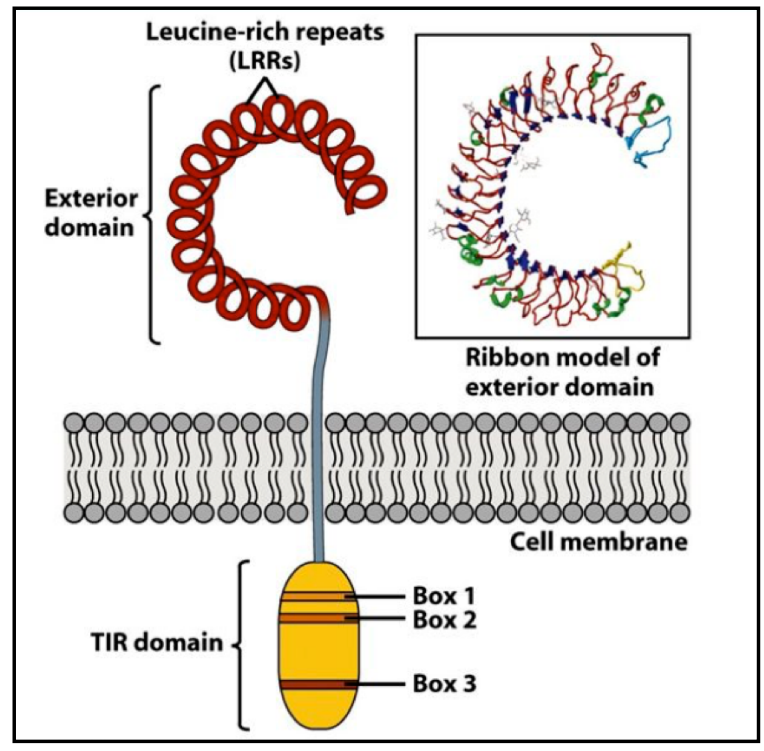

Figure 1 Structure of toll-like receptors (TLRs). The general structure of TLRs include: 1) An $N$-terminal exterior domain for ligand recognition 2) one transmembrane domain 3) A $C$-terminal intracellular signaling domain (similar to toll/interleukin domain) (11).

Signaling of TLRs starts with the detection and binding of PAMPs by the extracellular domain. When TLR is bound, Myeloid Differentiation 88 (MyD88) recruits IL-1R associated Kinase Protein (IRAK-1), IRAK-4 and TNF- $\alpha$ Receptor-Associated Factor 6 (TRAF6) to make a receptor complex. IRAK-1 causes ubiquitination of TRAF6 and 
mediates activation of TGF- $\beta$-activated kinase 1 (TAK1) which is needed for NF- $\kappa \mathrm{B}$ and Mitogen-Activated Protein Kinase (MAPK) activation. Activated TAK1 results in phosphorylation of IкB Kinase (IKK) and MAPK Kinase 6 resulting in degradation of the $\mathrm{NF}-\kappa \mathrm{B}$ inhibitor, I $\kappa \mathrm{B} \alpha$. This leaves NF- $\kappa B$ free to translocate to the nucleus so it can regulate gene expression. $\mathrm{NF}-\kappa \mathrm{B}$ is composed of $\mathrm{p} 50$ and p65 subunit proteins, which are held in the cytoplasm by the inhibitory $\mathrm{I} \kappa \mathrm{B} \alpha$ subunit. $\mathrm{NF}-\kappa \mathrm{B}$ is stimulated by many inflammatory signals including cytokines, MSU crystals and the inflammatory-stimuli induced phosphorylation-dependent degradation of $\mathrm{I} \kappa \mathrm{B} \alpha$ that allows the translocation of $\mathrm{NF}-\kappa \mathrm{B}$ to the nucleus to mediate inflammation and decrease apoptosis. The TLR signaling also includes MAPKs which are three types: ERK, JNK and p38 which can be activated separately or together. ERK and p38 are essential for production of pro-inflammatory cytokines as TNF- $\alpha$ and IL-1 (figure 2) $(17,18)$. Since phosphorylation is a critical step in activation of TLR-NF- $\kappa$ B pathway for the activation of NF$\kappa \mathrm{B}$, phagocytosis and recognition of MSU crystals by the

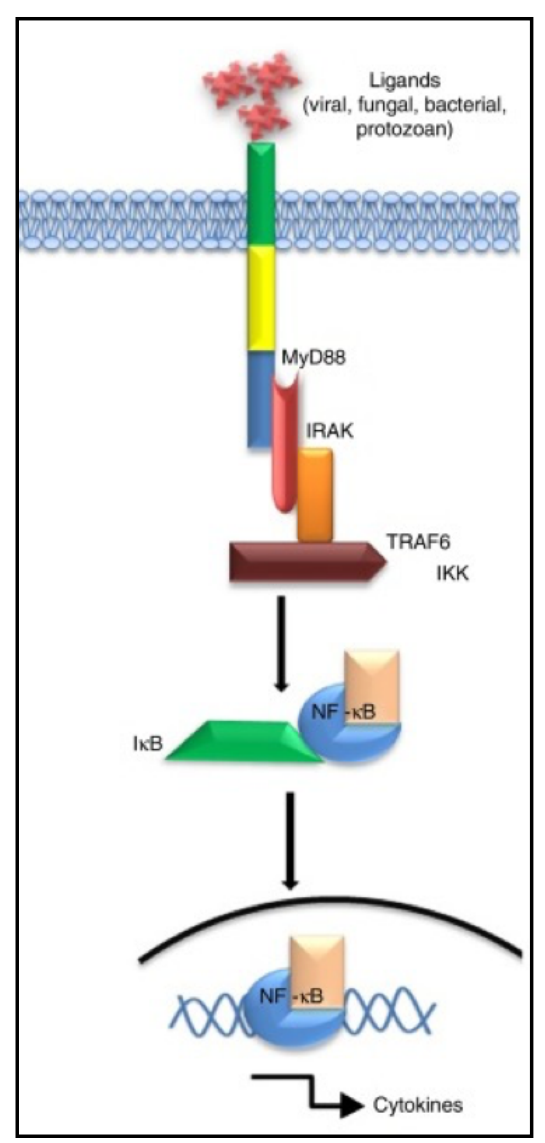

Figure 2 Toll-like Receptor (TLR) Signaling Pathway. The signaling pathway is initiated by binding of ligands to TLR receptor resulting in activation of MyD88 and recruitment of IRAK and TRAF6 to make a receptor complex. This receptor complex phosphorylates IKK. IKK degrades inhibitory IKB releasing NF- $\mathrm{BB}$. Active $\mathrm{NF}-\kappa \mathrm{B}$ is translocated to the nucleus causing transcription of proinflammatory cytokines (17).

TLR receptors leading to pathway protein phosphorylation could be due to the suppression of the activity of intracellular protein phosphatase 2A (PP2A). 
Pathogenesis of gout is a two-step process that begins with the NLRP3 inflammasome which is a multi-protein complex composed of NLR protein, adapter ASC (apoptosis-associated speck-like protein containing a caspase recruitment domain) and pro-caspase-1. Activation of

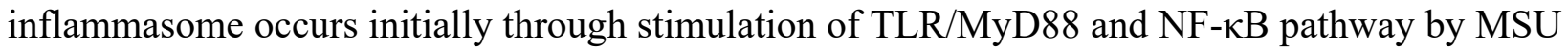
crystals leading to transcription of pro-IL-1 $\beta$ gene, while the second step is the assembly of the multi-protein complex composed of NLR protein, ASC and pro-caspase-1 following activation by pathogen associated molecular patterns (PAMPs) and/or damage associated molecular patterns (DAMPs). Subsequently, caspase-1 cleaves pro-IL-1 $\beta$ to mature IL-1 $\beta$, which is biologically active and is released extracellularly. The activation pathway of macrophages by MSU crystals is shown in figure 3. In addition, MSU cause secretion of ATP and activation of P2X7 receptor causing efflux of potassium extracellularly which contributes to inflammasome activation (19). TLR4 plays an important role in gout as IL-1 $\beta$ production decreased significantly in acute gouty arthritis patients after blockage of the receptor using anti-TLR4 antibody (20). Priming of the TLR4 receptor may occur through the effect of PAMPs, DAMPs, lipopolysaccharide (LPS) or uric acid (in soluble or crystalline form).

Uric acid (urate) crystals deposited in the joint cavity are phagocytosed by synovial macrophages leading to production of pro-inflammatory cytokines such as IL-1ß and TNF- $\alpha$. While welldifferentiated macrophages can engulf MSU crystals without initiating an inflammatory response, less-differentiated monocytes produce increased levels of inflammatory cytokines:

IL-1 $\beta$, TNF- $\alpha$, IL-6 and IL-8. An acute gout attack is of a self-limiting episode as it resolves from hours to days after macrophages uptake and remove of crystals hence reducing macrophage activation and release of chemokines. Furthermore, macrophages remove apoptotic cell bodies, 
produce TGF- $\beta$ and removes IL-1 to stop inflammation. Terminating acute attack includes production of anti-inflammatory cytokines, breakdown of pro-inflammatory cytokines, reduction of expression of receptors of inflammatory cytokines on leukocytes $(2,20)$.

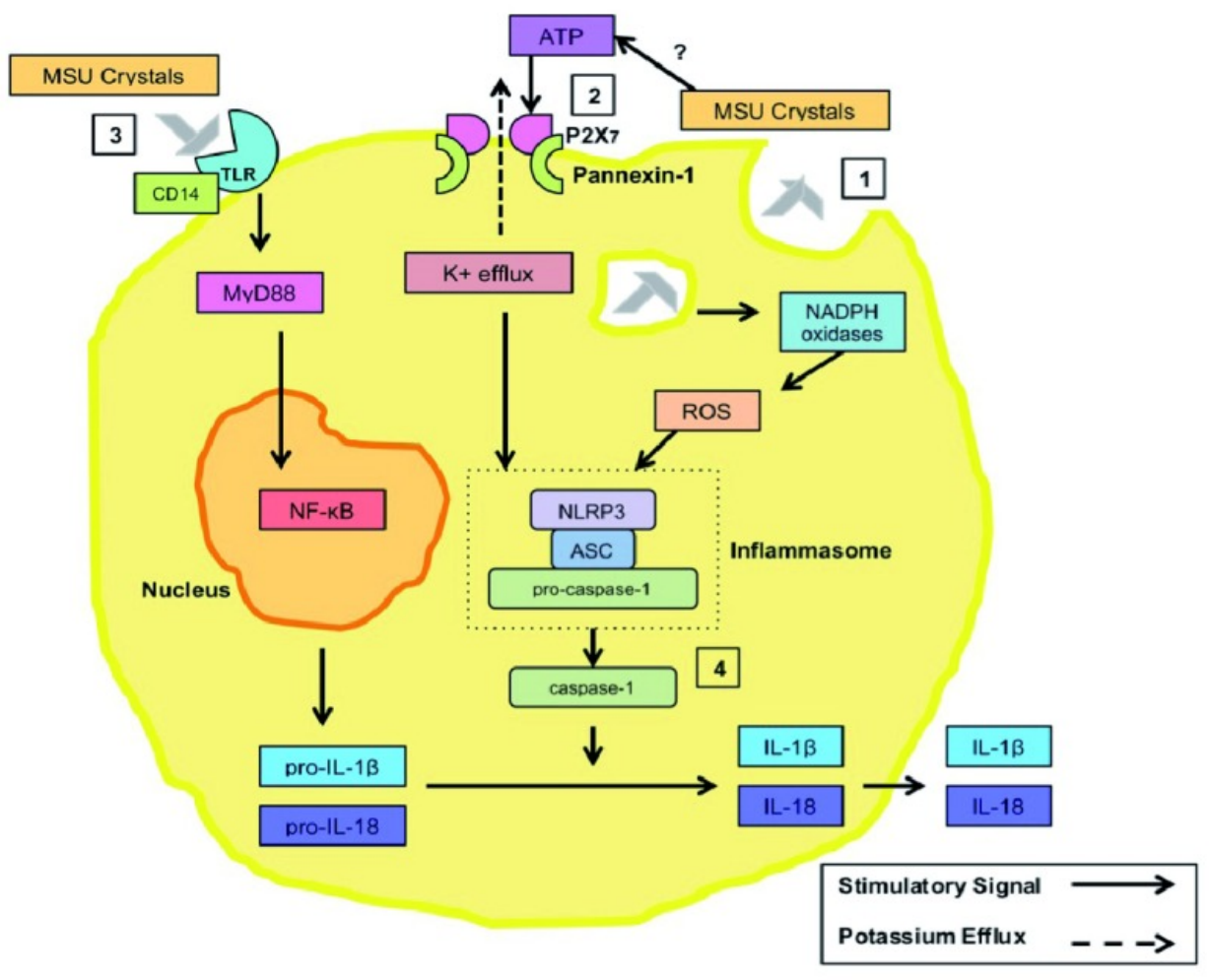

Figure 3 Production of IL- $\beta$ following NLRP3 Activation in response to monosodium urate crystal challenge. The steps of the pathogenesis are summarized as: 1) Phagocytosis of MSU and stimulation of NADPH oxidase leading to production of ROS and activation of NLRP3 inflammasome. 2) Secretion of ATP to interact with purinergic receptor P2X7 on pannexin-1 channels leading to potassium efflux and lower intracellular potassium that can also lead to NLRP3 activation. 3) Interaction of MSU with TLRs and activation of MyD88-and NF- $\mathrm{KB}$ pathway leading to transcription pro-IL-1 $\beta$ gene. 4) Finally, caspase-1 cleaves pro-IL-1 $\beta$ to IL-1 $\beta$, which is released extracellularly (19).

IL-1 is a large family of cytokines (cell signaling proteins) that play a role in innate immune responses for defense against pathogens. They increase the expression of adhesion factors on immune cells to increase their efflux to the site of inflammation. IL-1 $\beta$ is synthesized through 
$\mathrm{NF}-\kappa \mathrm{B}$ transcription in the nucleus resulting in the production of the biologically inactive pro-IL$1 \beta$ polypeptide. Post-translational modification by caspase- 1 cleaves pro- IL- $1 \beta$ to generate the mature pro-inflammatory cytokine IL-1 $\beta$ which is released extracellularly to bind to interleukin 1 receptor type 1 (IL-1R1) with the help of the co-receptor IL-1 receptor accessory protein (IL1RAP) to make a trimeric complex. This results in recruitment of MyD88, Tollinteracting protein (TOLLIP) and IRAK-4. A stable complex is created between IL-1 $\beta$, IL-1R1, IL-1RAP, MyD88 and IRAK-4. This results in a downstream cascade of phosphorylation steps which result in $\mathrm{NF}-\kappa \mathrm{B}$ activation

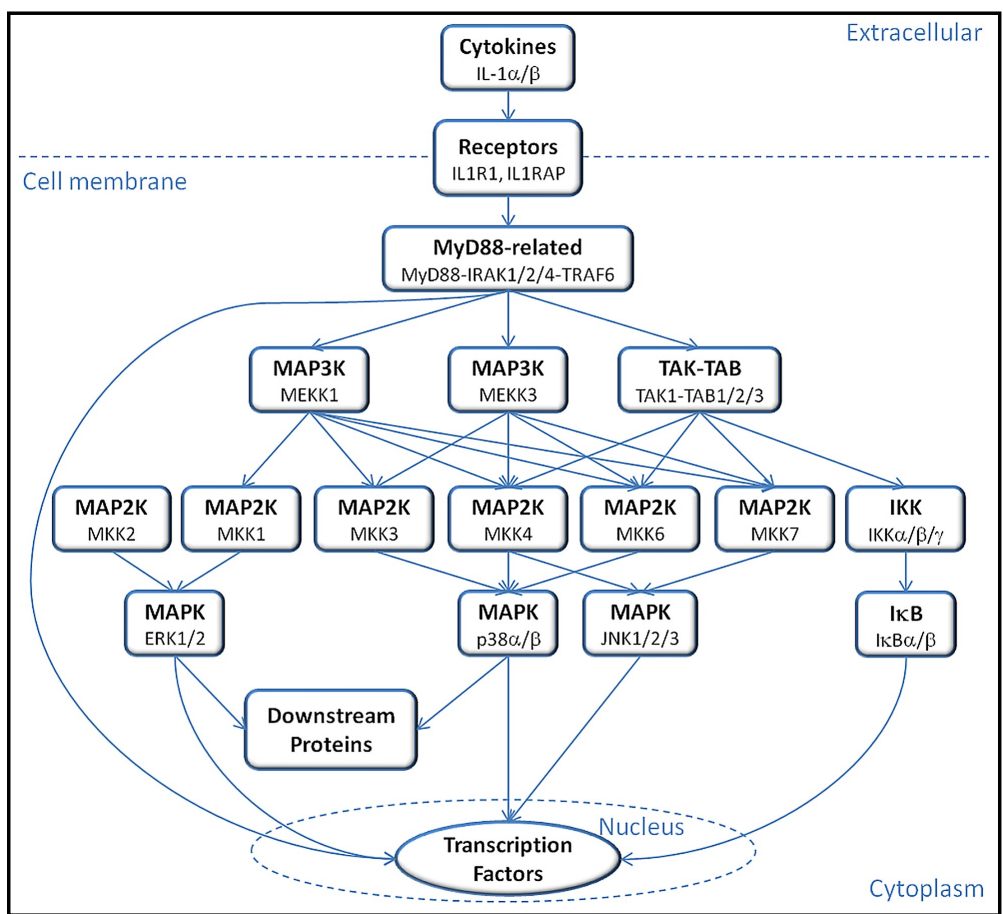

Figure 4 Interleukin-1 beta (IL-1 $\beta$ ) signaling pathway. Binding of IL-1 $\beta$ to its receptor activates the MAPK and ERK pathways resulting in $\mathrm{I} \kappa \beta$ degradation and NF- $\kappa \mathrm{B}$ nuclear translocation (17).

and release of the transcription factors inducing mRNA expression of hundreds of inflammatory cytokines including themselves through a positive feedback loop (figure 4) $(21,22)$.

\subsection{The proinflammatory mechanism of soluble uric acid.}

Uric acid is recognized as a disease-associated molecular pattern (DAMP) released from dying cells. The mechanism by which soluble uric acid (UA) causes inflammation is still debatable. In some perspectives, uric acid acts as an antioxidant. In others, it is a pro-oxidant molecule, which 
acts as a DAMP on TLRs activating the NF- $\kappa \mathrm{B}$ signaling pathway. Also, it reduces the availability of nitric oxide and increases the production of reactive oxygen species, induces

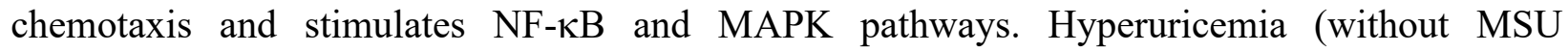
deposition) was highly associated with disorders such as hypertension and kidney disease which share the common factor of a 'redox imbalance' (16). A popular theory posits that UA causes state changes in cellular redox and increases the production of ROS leading to NLRP3 activation and eventually production of IL-1 $\beta$. In one study, UA was also found to be responsible for increasing the production of IL-1 $\beta$ through the NLRP3 and MyD88 pathways (18). In that study, bone marrow derived macrophages were incubated in the presence of UA alone or in combination with LPS for 24 hours. It was observed that the UA+LPS treatment induced higher IL-1 $\beta$ expression compared to control cells and cells stimulated with UA or LPS alone (23).

\subsection{Protein phosphatase-2A (PP2A) plays a key role in regulating intracellular inflammatory signaling pathways.}

In cells, one third of proteins' functions are regulated by phosphorylation and that leads to control of various cell functions. Based upon the physiological requirements of the cell, proteins shift between phosphorylated and dephosphorylated states using protein kinases and phosphatases (24). The family of protein phosphatases is divided mainly into two groups named as protein serine/threonine phosphatases (PSPs) and phosphotyrosine phosphatase (PTPs). PSPs include protein phosphatase-1 (PP1) and protein phosphatase 2A (PP2A) $(25,26)$. PP2A was found to be involved in critical processes regarding cellular growth, cell cycle, DNA replication,

transcription and translation, cell proliferation, apoptosis, signal transduction, cell mobility and cytoskeleton dynamics which made it a major target for therapy in cancer, heart, 
neurodegenerative diseases and diabetes research $(25,26)$. PP2A is a complex composed of three subunits: scaffold subunit (A), catalytic subunit (C) which can exist independently forming an active core dimer and a variable regulatory subunit (B) making a heterotrimer complex (27). Activation of PP2A leads to initiation of multiple signaling pathways leading to apoptosis in cancer, modulation of cell growth and survival. (figure 5) (28). One study found that serum levels of proinflammatory cytokines TNF- $\alpha$ and IL-6 increased in PP2A knock out mice following challenge with LPS (29). This was associated with increased phosphorylation in the MAPK pathways and the NF- $\kappa B$ pathway in bone marrow derived macrophages from knock out mice. Authors concluded that PP2A played an essential role in regulation of inflammation in the site of a septic insult through its targeting of MyD88 and Toll/IL-1R domain-containing adaptor (29). Taken all evidence together, it is plausible to expect that activation of PP2A could lead to reduction of inflammation in gout.

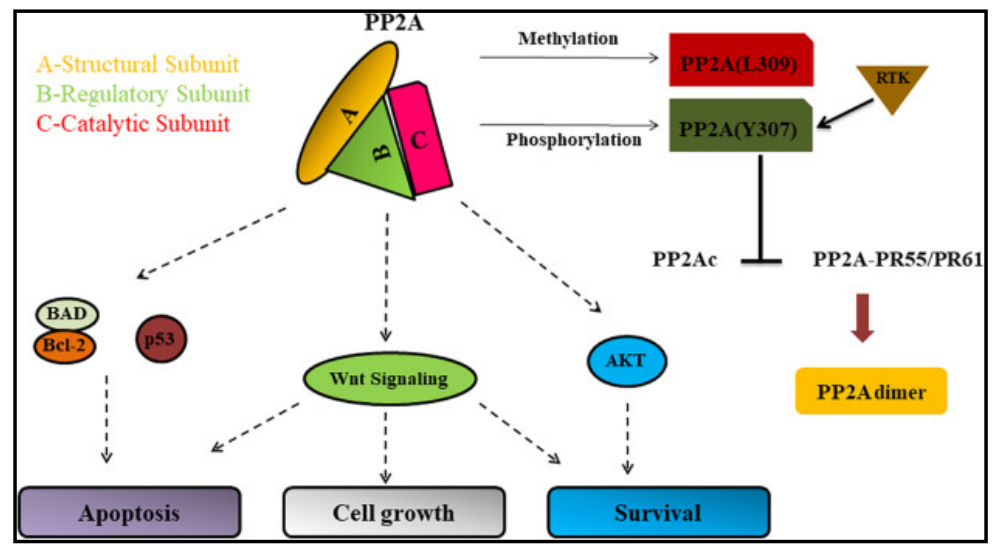

Figure 5 Regulation of protein phosphatase-2A (PP2A) and its associated signaling pathways. PP2A is composed of three subunits: structural, regulatory and catalytic. PP2A regulates multiple pathways including p53, Wnt and AKT pathways (28). 


\subsection{Clinically-available PP2A activators show efficacy in models of inflammation.}

Fingolimod (FTY720) is an oral treatment for multiple sclerosis. Fingolimod is a prodrug that is converted to the active metabolite Fingolimod phosphate (FTY720-P) by the enzyme sphinogsine kinase (figure 6). FTY720-P looks like the natural ligand sphingosine-1-phosphate (S1P), which is a lipid mediator present extracellularly to S1P cognate $\mathrm{G}$ protein-coupled receptors. S1P subtype $1\left(\mathrm{~S}_{1} \mathrm{P}_{1}\right)$ regulates the lymphocytes migration to circulation from lymphoid tissues and hence plays a major role in immunity. When FTY720-P binds to

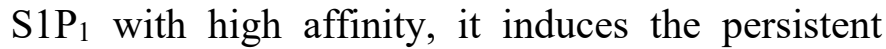
internalization of the receptor and thus antagonizes

S1P-driven migration of lymphocytes from lymphoid tissues. (30). FTY720 was found to block the PP2A inhibitor protein SET and thereby

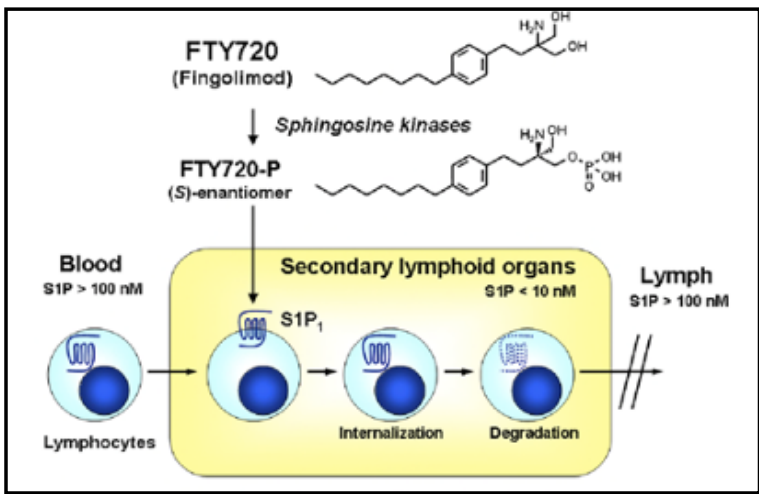

Figure 6 Phosphorylation of Fingolimod (FTY720) to Fingolimod phosphate (FTY720-P) and interaction with the $\mathrm{S}_{1} \mathrm{P}_{1}$ receptor.

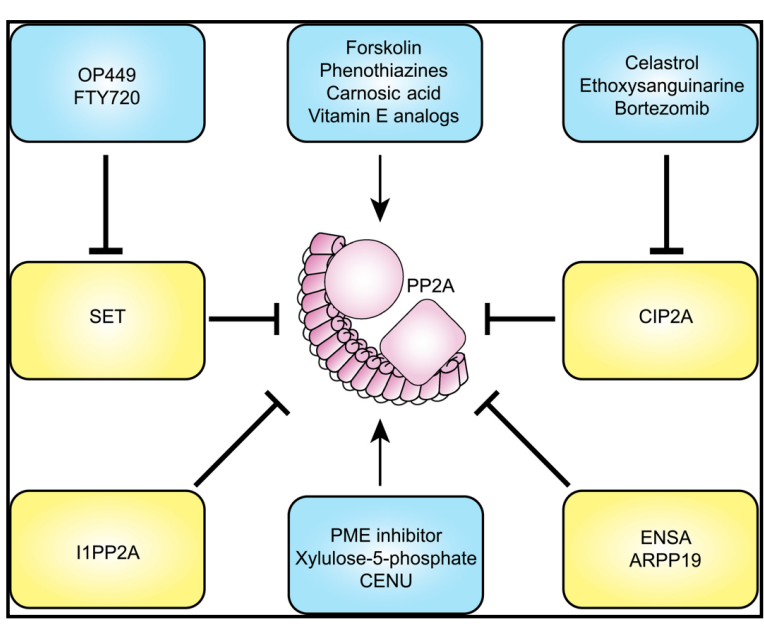

Figure 7 Activation of protein-phosphatse-2A by fingolimod (FTY720) via inhibition of SET protein (30).

enhancing the activity of PP2A figure 7 (31,32). In one study, activation of PP2A with FTY720 $(2.5 \mu \mathrm{M})$ has either limited or prevented tissue injury and inflammation in injury models of acute respiratory distress syndrome (ARDS) leading to decreased production of the chemokine interleukin-8 (IL-8) $(33,34)$. Therefore, FTY720-P can be used as a research tool to examine 
whether activating PP2A leads to decreased inflammation in gout as illustrated by decreased production of IL-1 $\beta$ by MSU challenged monocytes/macrophages (35).

\section{Hypothesis}

UA and LPS prime peripheral blood monocytes resulting in enhancement of MSU crystal phagocytosis and downstream production of inflammatory cytokines and PP2A is a critical regulator of this priming effect.

\subsection{Aim 1:}

To examine the activating effect of UA and LPS on MSU crystal phagocytosis and downstream activation of NLRP3 inflammasome, NF- $\mathrm{KB}$ and IL-1 $\beta$ expression and production in THP-1 monocytes and test whether this effect is associated with a reduction in intracellular PP2A activity.

\subsection{Aim 2:}

To study the role of PP2A in regulating crystal-induced inflammation in monocytes and evaluate the utility of a PP2A-activating drug, fingolimod phosphate (FTY720-P), in providing an antiinflammatory activity in MSU stimulated monocytes. 


\section{Materials and Methods}

Human monocytes (THP-1)

Human monocyte cells (THP-1, ATCC, USA) were cultured in $10 \%$ FBS, $1 \%$ penicillin/streptomycin RPMI-1640 media and 2-Mercaptoethanol as per ATCC recommendation in $\mathrm{T} 75$ flask to a density of $1.5 \times 10^{6}$ cells $/ \mathrm{mL}$ in $37^{\circ} \mathrm{C}$ and $5 \% \mathrm{CO}_{2}$.

\subsection{Reagents}

Monosodium urate monohydrate (MSU) crystals

Pyrogen-free MSU crystals (Invivogen, USA) were resuspended with sterile phosphate buffered saline (PBS) and maintained at $4^{\circ} \mathrm{C}$.

\section{Fingolimod hydrochloride (FTY720)}

Fingolimod hydrochloride (5 mg; Cayman Chemical; catalog \# 10006292, USA) were reconstituted with $1,000 \mu \mathrm{L}$ dimethyl sulfoxide (DMSO) to make a stock solution (14.5 mM) and stored at $-20^{\circ} \mathrm{C}$. At the time of experiment, an intermediate concentration of $500 \mu \mathrm{M}$ was made by adding $34.5 \mu \mathrm{L}$ from the stock solution to $965.5 \mu \mathrm{L}$ DMSO. Subsequently, $5 \mu \mathrm{L}$ from the intermediate stock solution were added to each $1,000 \mu$ media in wells to make final concentration of fingolimod $2.5 \mu \mathrm{M}$.

\section{Fingolimod phosphate (FTY720-P)}

Fingolimod phosphate (0.59 mg; Cayman Chemical; catalog \# 10008639, USA) was reconstituted with $10 \mathrm{~mL}$ dimethyl sulfoxide (DMSO) to make a stock concentration $(152.2 \mu \mathrm{M})$ 
and stored at $-20^{\circ} \mathrm{C}$. To make a final concentration of $2.5 \mu \mathrm{M}, 16 \mu \mathrm{L}$ of reconstituted solution were added to each $1,000 \mu \mathrm{L}$ media in well.

\section{$\underline{\operatorname{Uric} \text { Acid }(U A)}$}

Uric acid (U2625-25G, Sigma-Aldrich, USA) was solubilized as a concentration of $50 \mathrm{mg} / \mathrm{dL}$ in warm serum-free RPMI 1640 media.

\subsection{Phagocytosis of FITC labeled fluorescent beads in primed monocytes}

Monocytes were seeded in 24 -well plate $\left(0.6 \times 10^{6}\right.$ cells/well $)$ and were primed using $50 \mathrm{mg} / \mathrm{dL}$ uric acid and 10ng/ml LPS for 24 hours (36). Latex beads-rabbit IgG-FITC complex (7.5 $\mu 1 /$ well; Phagocytosis Assay Kit, Cayman Chemicals) were added directly into respective wells and incubated for 4 hours at $37^{\circ} \mathrm{C}$. Our experimental groups included: control unprimed monocytes ( \pm latex beads), and UA, LPS, UA and LPS-primed monocytes ( + latex beads). To assess phagocytosis, cells were centrifuged for five minutes at $400 \mathrm{xg}$, then they were resuspended in $300 \mu \mathrm{L}$ assay buffer. The proportion of monocytes that phagocytized fluorescent beads was assessed based on increased side scatter properties using BD FACSVerse Flow Cytometer.

\subsection{Phagocytosis of MSU crystals by primed monocytes}

Monocytes were seeded in 6-well plate $\left(0.5 \times 10^{6}\right.$ cells/well $)$ as control $( \pm$ MSU), and UA, LPS, UA and LPS (+ MSU). Cells were primed using 50mg/dL uric acid and 10ng/ml LPS for 24 hours (36). This was followed by 4 hours treatment with MSU crystals $(100 \mu \mathrm{g} / \mathrm{mL})$. Cells were collected, centrifuged for 3,000 rpm for five minutes. The supernatant was discarded and cells were suspended in $300 \mu \mathrm{L}$ PBS. Indirect assessment of MSU phagocytosis was determined by 
analyzing the change in cell side-scatter distribution due to crystal phagocytosis using a flow cytometer (BD FACSVerse). Two regions of interest were identified; P1 representing the monocyte population in the absence of MSU exposure and P2 representing the monocyte population with increased side scatter due to MSU phagocytosis. MSU-positive cells were calculated as the ratio of cells in the $\mathrm{P} 2$ region to the sum of cells in the $\mathrm{P} 1$ and $\mathrm{P} 2$ regions.

\subsection{IL-1ß gene expression in primed monocytes}

A total of 500,000 monocytes were plated per well in a 6-well plate. Cells were primed with UA and LPS for 24 hours at $37^{\circ} \mathrm{C}$ as described above. Cells were treated with MSU crystals $(100 \mu \mathrm{g} / \mathrm{mL})$ for 6 hours. After incubation, cells were collected, centrifuged at 3,000 rpm for 5 minutes to be pelleted. The supernatant was collected and stored at $-20^{\circ} \mathrm{C}$ while total RNA was extracted using trizol reagent (Thermo Fisher Scientific, USA) and mRNA concentrations were determined using Nanodrop One Microvolume UV-Vis spectrophotometer (Thermo Scientific, USA). cDNA was synthesized using iScript ${ }^{\mathrm{TM}}$ cDNA Synthesis Kit (Biorad, USA). qRT-PCR was done by Quantstudio ${ }^{\mathrm{TM}} 3$ Real-Time PCR System (Thermo Fisher Scientific, USA) with TaqMan ${ }^{\circledR}$ Fast Advanced Master Mix (Life Technologies, USA). The probes were labeled with 6-carboxyfluorescein (6-FAM). The primers used in PCR are listed in Table 1. The cycle threshold $(\mathrm{Ct})$ values of the gene of interest were normalized with the value of GAPDH of the same sample, and the relative expression of each gene was analyzed using the $2^{-\Delta \Delta C t}$ method (37).

\begin{tabular}{|l|l|l|}
\hline Gene & Forward (5' to 3') & Reverse (5' to 3') \\
\hline GAPDH & ACTGGCGTCTTCACCACCAT & AAGGCCATGCCAGTGAGCTT \\
\hline IL-1; & TTGTTGCTCCATATCCTGTCC & CACATGGGATAACGAGGCTT \\
\hline PP2Ac & TCGTTGTGGTAACCAAGCTG & AACATGTGGCTCGCCTCTAC \\
\hline
\end{tabular}

Table 1 Primers used for gene amplification 


\subsection{IL-1ß production by primed THP-1 monocytes}

Monocytes (500,000 cells per well) were seeded in 6-well plates and primed with UA and LPS for 24 hours as described above. Then, they were stimulated with MSU (100 $\mu \mathrm{g} / \mathrm{mL})$ for 6 hours. Media supernatants were collected and IL-1 $\beta$ concentration was measured using Human IL1beta/IL-1F2 Duoset ELISA kit (R\&D Systems; DY201-05, USA).

\subsection{PP2A knockdown using protein phosphatase-2A catalytic subunit (PP2Ac) siRNA}

Monocytes $\left(1.0 \times 10^{-6}\right.$ cells/well $)$ were seeded in 6 well plates using Opti-MEM ${ }^{\mathrm{TM}}$ Reduced Serum Medium (Thermo Fisher; 31985088, USA) and labeled as control, PP2A siRNA and negative control. PP2CA siRNA (Thermo fisher Scientific; AM16708, USA) and Silencer ${ }^{\mathrm{TM}}$ Negative Control siRNA (Thermo fisher Scientific; AM4611, USA) were reconstituted and added to their respective wells at concentration of $3 \mu \mathrm{M}$ with $9 \mu 1$ of Lipofectamine ${ }^{\mathrm{TM}} 3000$ Transfection Reagent (Invitrogen; L3000001, USA) in a total volume of $2500 \mu 1 /$ well and transfection was left for 24 hours at $37^{\circ} \mathrm{C}$. PP2A knockdown was confirmed using gene expression. First, total RNA was extracted using trizol reagent (Thermo Fisher Scientific, USA) and mRNA concentrations were determined using Nanodrop One Microvolume UV-Vis spectrophotometer (Thermo Scientific, USA). cDNA synthesis and qPCR assays were performed as described above. The probes were labeled with 6-carboxyfluorescein (6-FAM). The primers used in PCR are listed in Table 1. The cycle threshold $(\mathrm{Ct})$ values of the gene of interest were normalized with the value of GAPDH of the same sample, and the relative expression of each gene was analyzed using the $2^{-\Delta \Delta \mathrm{Ct}}$ method. The relationship between PP2A expression and PP2A activity was established by measuring PP2A activity following PP2A knockdown. After 24 transfecting THP-1 cells for 24 hours, transfected cells were collected, 
centrifuged at 3,000 rpm for five minutes, pelleted and lysed using RIPA Buffer with protease inhibitor and then re-centrifuged at 14,000 rpm for ten minutes. The protein isolate was collected and stored at $-80^{\circ} \mathrm{C}$. Protein levels were measured using Pierce ${ }^{\mathrm{TM}}$ BCA Protein Assay Kit (Thermo Fisher Scientific; 23225, USA). A total of $5 \mu \mathrm{L}$ of each sample was mixed with $195 \mu \mathrm{L}$ RIPA buffer and protease inhibitor in microcentrifuge tubes then $75 \mu \mathrm{L}$ were added in 96 -well plates in duplicate wells. Working reagent $(75 \mu \mathrm{l})$ were added to each well and mixed on shaker for 30 seconds then plate was covered and incubated at $37^{\circ} \mathrm{C}$ for 30 minutes. Absorbance was measured at $562 \mathrm{~nm}$. After determining protein levels, $5 \mu \mathrm{g} /$ well protein was used to measure PP2A activity using the PP2A immunoprecipitation kit (Sigma Aldrich, USA). Protein samples were added to $4 \mu \mathrm{L}$ anti-PP2A C subunit and $30 \mu \mathrm{L}$ protein A agarose slurry then the volume was brought to $120 \mu \mathrm{L}$ with the assay buffer. Samples were incubated on shaker for 3 hours at $4^{\circ} \mathrm{C}$. Agarose beads were then washed 3 times with $400 \mu \mathrm{L}$ 1X TBS and once with $200 \mu 1$ assay buffer. A phosphopeptide substrate $(40 \mu \mathrm{L})$ were added to the beads and $20 \mu \mathrm{L}$ assay buffer. The mixture was incubated for ten minutes at $30^{\circ} \mathrm{C}$ on a shaking incubator then centrifuged and $25 \mu \mathrm{L}$ of supernatants were added to each well in 96-well plate in duplicates. For color development, $100 \mu \mathrm{L}$ of malachite green phosphate detection solution were added to each well. Absorbance was measured at $650 \mathrm{~nm}$.

\subsection{IL-1ß expression and production in PP2Ac siRNA-treated THP-1 monocytes following incubation with MSU crystals}

Monocytes $\left(1.0 \times 10^{-6}\right.$ cells/well) were seeded in 6 well plates using Opti-MEM ${ }^{\mathrm{TM}}$ Reduced Serum Medium (Thermo Fisher; 31985088, USA) and labeled as control ( \pm MSU), PP2A siRNA and negative control (+MSU). PP2CA siRNA (Thermo fisher Scientific; AM16708, USA) and 
Silencer $^{\mathrm{TM}}$ Negative Control siRNA (Thermo fisher Scientific; AM4611, USA) were reconstituted and added to their respective wells at concentration of $3 \mu \mathrm{M}$ with $9 \mu \mathrm{L}$ of Lipofectamine $^{\mathrm{TM}} 3000$ Transfection Reagent (Invitrogen; L3000001, USA) in a total volume of $2,500 \mu \mathrm{L} /$ well and transfection was left for 24 hours at $37^{\circ} \mathrm{C}$. MSU crystals $(100 \mu \mathrm{g} / \mathrm{mL})$ were then added to their respective wells. Cells were collected, centrifuged, pelleted and media supernatants were collected and IL-1 $\beta$ gene expression and media concentrations were determined as described above.

\subsection{Impact of FTY720 and FTY720-P treatments on intracellular PP2A activity in human} THP-1 monocytes

THP-1 monocytes $\left(0.4 \times 10^{6}\right.$ cells per well) were seeded in 6 well plates. FTY720 $(2.5 \mu \mathrm{M})$ and FTY720-P $(2.5 \mu \mathrm{M})$ were added and cells were collected at 1 hour, 3 hours, 6 hours and 24 hours. PP2A immunoprecipitation and PP2A activities were determined as described above.

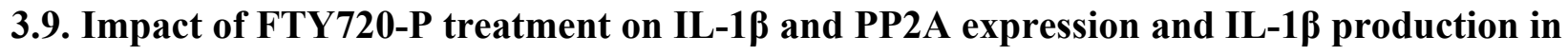 MSU-treated primed THP-1 macrophages}

A total of 500,000 THP-1 monocytes were plated per well in 6-well plates. Monocytes were primed with UA and LPS for 24 hours at $37^{\circ} \mathrm{C}$ as described above. Cells were treated with MSU crystals $(100 \mu \mathrm{g} / \mathrm{mL})$ for 6 hours with and without pre-incubation with FTY720-P (3 hours; $2.5 \mu \mathrm{M})$. After incubation, cells were collected, centrifuged at 3,000 rpm for 5 minutes to be pelleted. Supernatants were collected and stored at $-20^{\circ} \mathrm{C}$. RNA isolation, cDNA synthesis and qPCR were performed as described above. Genes of interest included PP2Ac and IL-1 $\beta$ using 
GAPDH as a reference gene. IL- $1 \beta$ levels in media supernatants were quantified as described above.

\subsection{Impact of FTY-720-P on THP-1 cell viability}

To rule out the possibility that FTY720-P's effect is due to a cytotoxic effect on THP-1 monocytes, monocytes $(25,000 /$ well $)$ were seeded in 96 -well plate in $100 \mu \mathrm{L}$ per well in triplicate wells as the following groups: background $(100 \mu \mathrm{L}$ culture medium), low background $(100 \mu \mathrm{L}$ culture medium and monocytes), positive control $(100 \mu \mathrm{L}$ culture medium and monocytes with 10 $\mu \mathrm{L}$ Cell Lysis Solution), experimental groups including MSU \pm FTY720-P and MSU (UA+LPS) \pm FTY720-P. Priming was done with UA and LPS as described above for 24 hours. Cell cytotoxicity was determined using lactate dehydrogenase (LDH) Assay Kit (Abcam; ab65393, USA). Cells were pre-incubated with FTY720-P for 3 hours then treated with MSU crystals for 6 hours. Then cell lysis solution was added to positive control and incubated for ten minutes. The microtiter plate was centrifuged at $600 \mathrm{xg}$ for ten minutes then clear medium solution $(10 \mu \mathrm{L} /$ well $)$ was transferred into optically clear 96-well plate. The LDH reaction mix $(100 \mu \mathrm{L} /$ well) was added to quantify the release of intracellular LDH, which occurs upon damage to cell membrane. Absorbance of all controls and samples was at $450 \mathrm{~nm}$ and the formula used to calculate percent cell cytotoxicity was: Cytotoxicity $(\%)=(($ Test Sample - Low Control $) /($ High Control - Low Control) $) * 100$.

\subsection{Statistical Analyses}

Statistical analyses of gene expression data were performed using $\Delta C t$ values $\left(C_{t}\right.$ target gene- $C_{t}$ GAPDH) for each gene of interest in each experimental group. Continuous variables were 
initially evaluated whether they satisfied the requirements for parametric statistical tests. Statistical significance comparing two groups or multiple groups with parametric data was assessed by Student's $t$ test or ANOVA followed by post-hoc multiple comparisons using Tukey's post-hoc test. Statistical significance comparing two groups or multiple groups with nonparametric data was assessed by Rank Sum test or ANOVA on the ranks. A $p$ value of $<$ 0.05 was considered statistically significant. Data are presented as scatter plots with mean and standard deviations highlighted. Data were generated from at least 3 independent experiments with duplicate wells per treatment.

\section{Results}

\subsection{Impact of UA+LPS priming on phagocytosis of fluorescent beads and MSU crystals by}

\section{THP-1 monocytes}

Using the fluorescent beads phagocytosis assay, we observed that priming with LPS alone or

LPS + UA increased bead

phagocytosis by THP-1

monocytes. Representative

flow cytometry plots depict

increased shift of fluorescently

labeled cell population in LPS-

treated and LPS + UA-treated

THP-1 monocytes compared to

control unprimed cells (figure

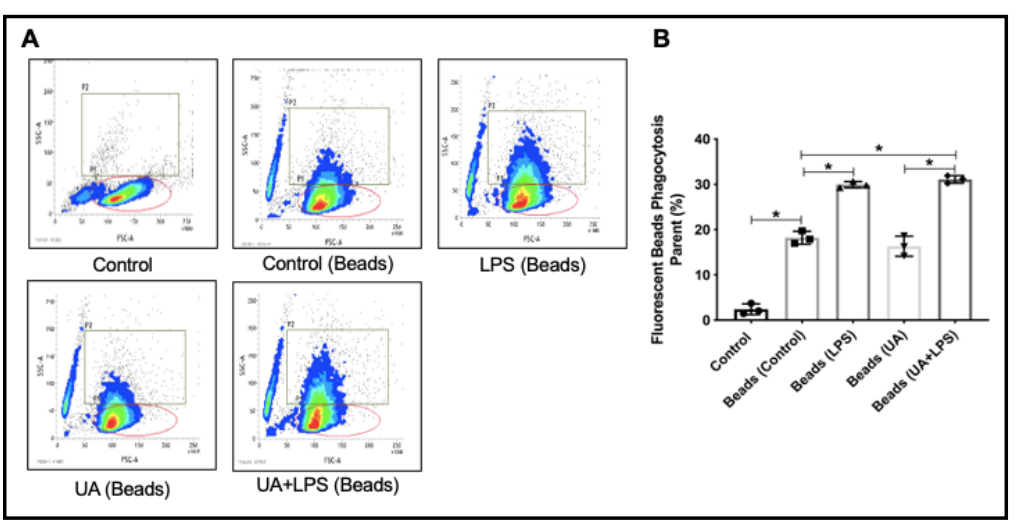

Figure 8 Impact of soluble uric acid and lipopolysaccharide priming on phagocytosis of FIT-C labeled beads by THP-1 monocytes. A) Representative flow cytometry scatter plots showing enhanced latex beads phagocytosis (as shown by more cells with increased side scatter in $\mathrm{P} 2$ region of interest) by THP-1 monocytes. B) Quantitative determination of beads phagocytosis using $\%$ positive cells in $\mathrm{P} 2$ region of interest. Priming of monocytes with LPS and UA significantly increased beads phagocytosis by THP-1 monocytes. ${ }^{*} p<0.001,{ }^{*} p<0.01$. 
8A). The enhancement in cell phagocytic behavior appeared to be due to LPS priming as phagocytosis of beads by UA-primed monocytes was not different $(p>0.05)$ from beads' phagocytosis by control cells (figure 8B). On the other hand, LPS alone or LPS + UAprimed monocytes exhibited significantly higher $(p<0.001)$ phagocytic activity against fluorescent beads compared to control untreated monocytes (figure 8B).

Representative flow cytometry plots of MSU phagocytosis by THP-1 monocytes under control and UA and LPS priming conditions are presented in figure 9A. UA and LPS priming appeared to enhance MSU phagocytosis by THP-1 monocytes as illustrated by an increase in the percentage of THP-1 monocytes in the P2 region of interest compared to control unprimed monocytes. THP-1 monocytes did not exhibit a significant ability to phagocytose MSU crystals ( $p>0.05$ ) (figure 9B). However, UA and LPS priming increased MSU phagocytosis by THP-1 monocytes compared to unprimed monocytes $(p<0.001$; $p<0.01$ respectively). A combination of UA + LPS priming increased MSU phagocytosis by THP-1 monocytes and that effect was not significantly different from UA priming alone.

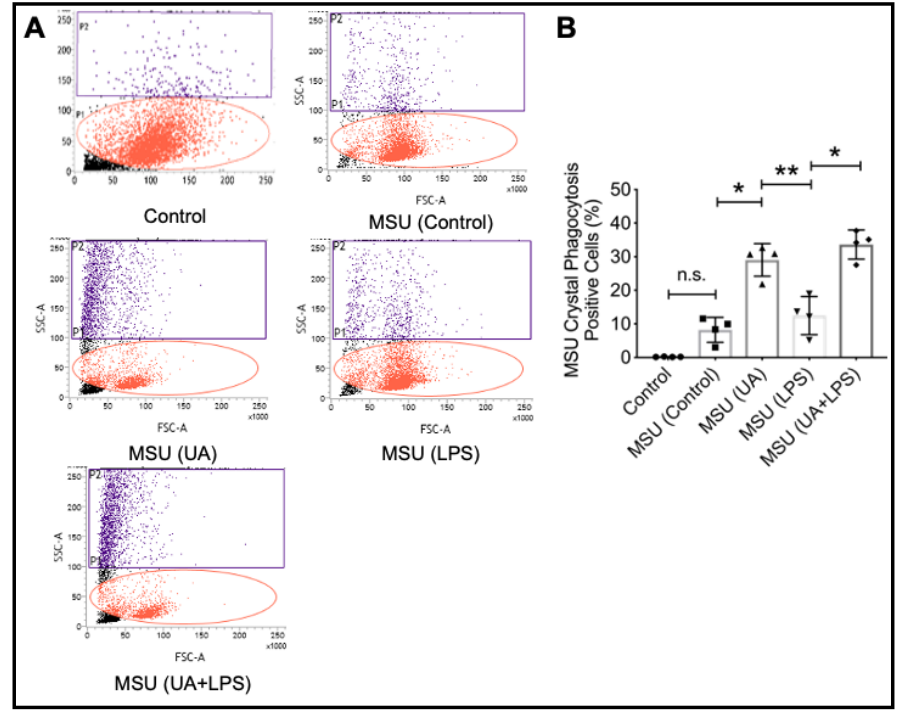

Figure 9 Impact of soluble uric acid and lipopolysaccharide priming on phagocytosis of monosodium urate (MSU) crystals by THP-1 monocytes. A) Representative flow cytometry scatter plots showing enhanced MSU crystal phagocytosis (as shown by more cells with increased side scatter in P2 region of interest) by THP-1 monocytes. B) Quantitative determination of MSU phagocytosis using \% positive cells in P2 region of interest. Priming of monocytes with LPS and UA significantly increased MSU phagocytosis by THP-1 monocytes. ${ }^{*} p<0.001,{ }^{* *} p<0.01$. 


\subsection{Impact of UA + LPS priming on intracellular PP2A activity, IL-1ß expression and}

\section{production}

Following priming with UA and LPS and subsequent treatment with MSU crystals for 6 hours, PP2A activity was significantly lower compared to UA+LPS $(p<0.05)$ (figure 10A). In contrast, UA + LPS priming did not alter intracellular PP2A activity compared to control monocytes $(p<0.05)$. UA + LPS priming significantly increased IL-1 $\beta$ expression and production in MSU stimulated monocytes ( $p<0.001$ for both comparisons) (figure 10B \& 10C respectively).

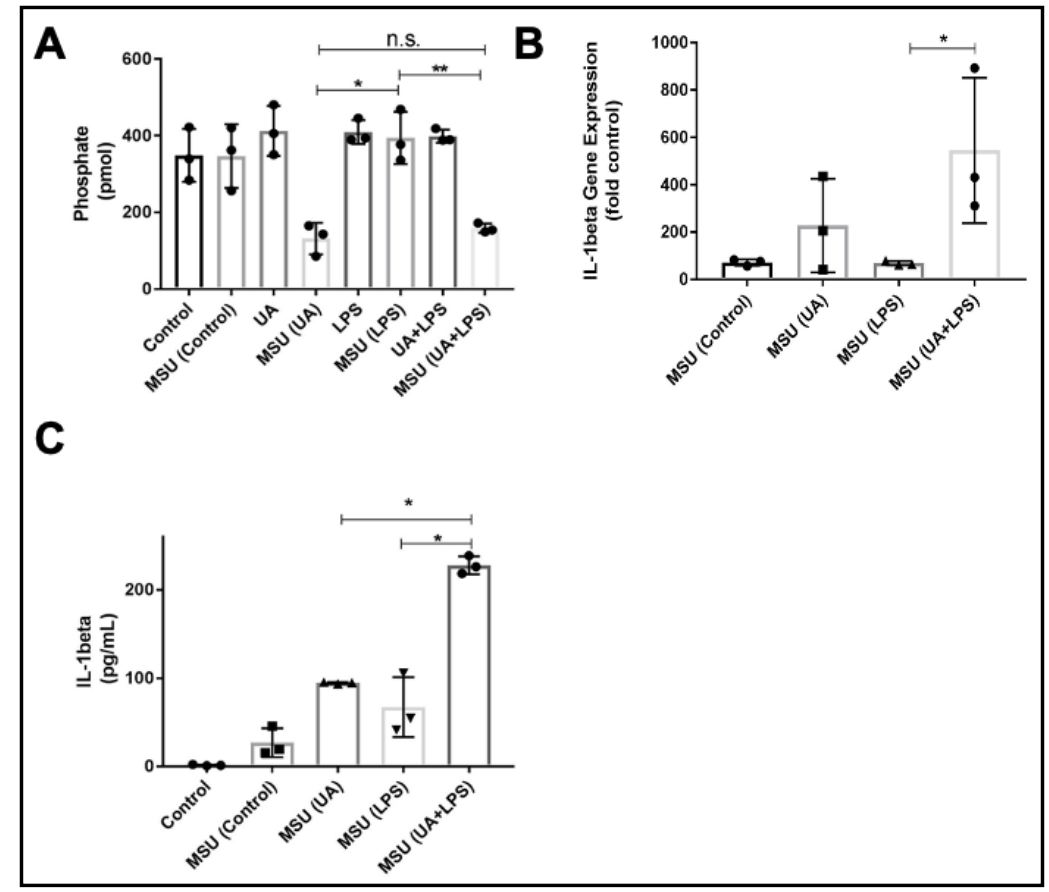

Figure 10 Impact of uric acid (UA) and lipopolysaccharide (LPS) priming on protein phoaphstase-2A (PP2A) activity, interleukin-1 beta (IL-1 $\beta$ ) expression and production in THP-1 monocytes. A) MSU challenge in UA+LPS primed monocytes resulted in a significant reduction in PP2A activity as measured by ability to generate phosphate from a phosphorylated peptide substrate. B) IL-1 $\beta$ expression in THP-1 monocytes following priming with UA or LPS and MSU challenge for 6 hours. C) IL-1 $\beta$ production in THP-1 monocytes following priming with UA or LPS and MSU challenge for 6 hours. A combination of LPS and UA priming resulted in a significant increase in IL-1 $\beta$ expression and production. ${ }^{*} p<0.001,{ }^{* *} p<0.01$, n.s. non-significant. 


\subsection{PP2A knockdown using PP2A siRNA and effect of knockdown on IL-1beta expression and production}

PP2A knockdown using PP2A siRNA for 24 hours resulted in a significant reduction in PP2A expression (figure 11A) compared to scramble siRNA $(\mathrm{p}<0.001)$. The magnitude of reduction in PP2A expression was approximately $60 \%$. PP2A activity following PP2A siRNA treatment showed significantly lower PP2A activity in knockdown cells compared to control and scramble siRNA (figure 11B). In PP2A-knockdown monocytes, MSU treatment resulted in a significant increase in IL-1 $\beta$ expression and production compared to untreated and scramble siRNA-treated THP-1 monocytes ( $\mathrm{p}<0.05$ for both comparisons) (figure 11C \& 11D).

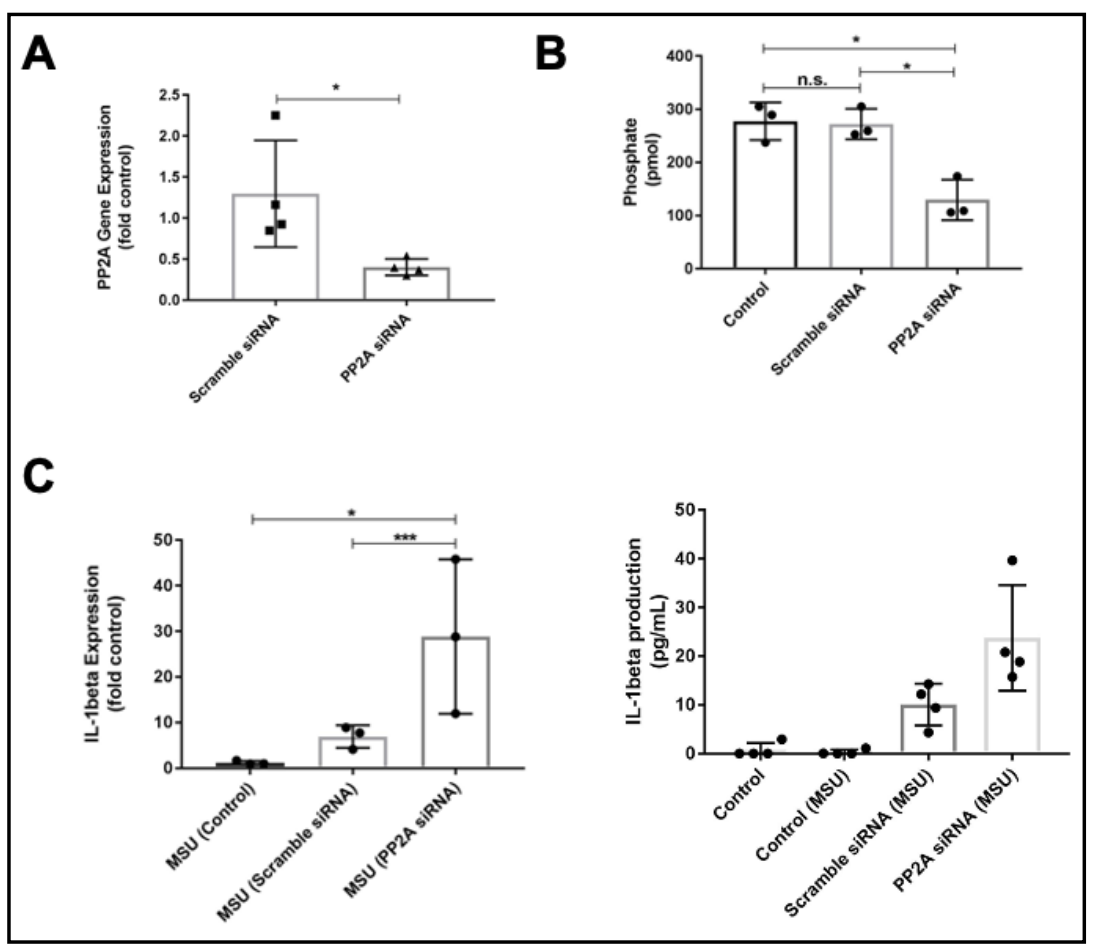

Figure 11 Impact of protein phosphatase-2A (PP2A) silencing on monosodium urate monohydrate (MSU) crystal -induced interleukin-1 beta (IL-1 $\beta$ ) expression and production by human THP-1 monocytes.

A) PP2Ac expression in THP-1 monocytes after PP2A siRNA knockdown. B) PP2A activity in THP-1 monocytes following PP2A siRNA knockdown. PP2A knockdown resulted in a reduction in PP2A activity. C) IL-1 $\beta$ expression in THP-1 monocytes following PP2A knockdown and MSU challenge for 6 hours. D) IL- $1 \beta$ production in THP-1 monocytes following PP2A knockdown and MSU challenge. PP2A knockdown enhanced IL-1beta expression and production in comparison to control and scramble stimulated with MSU crystals. ${ }^{*} p<0.001,{ }^{* *} p<0.01$, n.s. non-significant. 


\subsection{PP2A activation by FTY720 and FTY720-P at different time-points and FTY720-P enhancement of PP2A activity of primed monocytes}

The PP2A activity was determined at 1, 3, 6 and 24 following incubation with prodrug FTY720 or active metabolite FTY720-P (figure 12A and 12B). The peak activity for prodrug was at 6 hours incubation while peak activity of the active metabolite was at 3 hours after addition to monocytes (figure 12A and 12B). Priming of monocytes using UA and LPS resulted in significantly reduced PP2A activity compared to control $(p<0.01)$ and this reduction was reversed by the addition of PP2A activating drug FTY720-P $(p<0.05)$ (figure 12C).

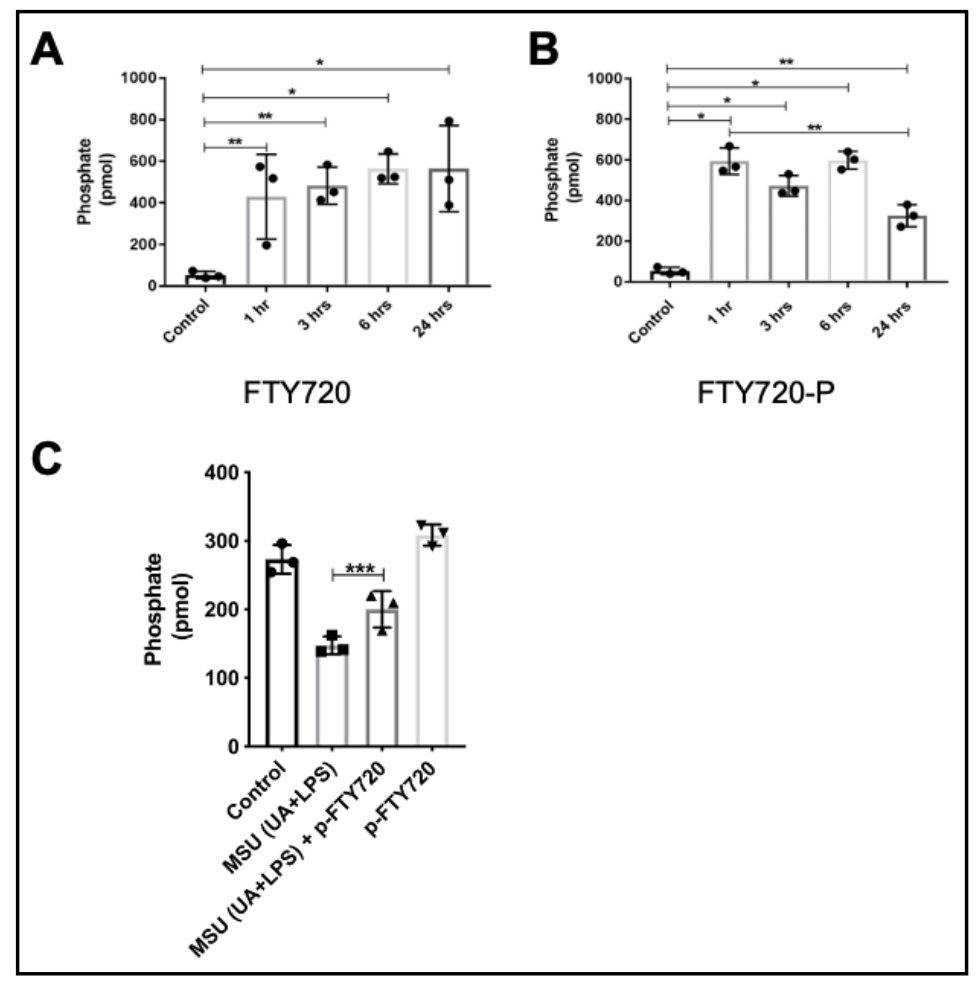

Figure 12 Impact of fingolimod prodrug (FTY720) and active phosphate metabolite (FTY720-P) treatments on intracellular protein phosphatase-2A (PP2A) activity in THP-1 monocytes. A) PP2A activity in FTY-720treated monocytes. B) PP2A activity in FTY720-P-treated monocytes. The highest activity of FTY720 was at 6 hours while FTY720-P had peak activity after 3 hours. C) PP2A activity in THP-1 monocytes following priming with UA or LPS and challenge with MSU \pm FTY720-P pre-incubation for 3 hours. The significant reduction in PP2A activity in primed monocytes was reversed by the addition of FTY720-P. PP2A activity was determined by its ability to generate phosphate from a phosphorylated peptide substrate. ${ }^{*} p<0.001,{ }^{* *} p<0.01$; $* * * p<0.05$. 


\subsection{Impact of FTY720-P on cell viability, PP2A expression, IL-1 $\beta$ expression and production in human THP-1 monocytes}

The impact of FTY720-P treatment on THP-1 monocyte viability, PP2Ac expression and IL-1 $\beta$ expression and production in UA + LPS primed and MSU treated THP-1 monocytes are presented in figure 13. There was no significant increase in cell cytotoxicity as a result of FTY720-P treatment (figure 13A) and FTY720-P treatment did not change the gene expression level of PP2Ac (figure 13B). In contrast, FTY720-P treatment reduced IL-1 $\beta$ expression $(p<0.001)$ (figure 13C) and mature IL-1 $\beta$ production $(p<0.001)$ (figure 13D) in UA+LPS pretreated human monocytes following MSU stimulation.

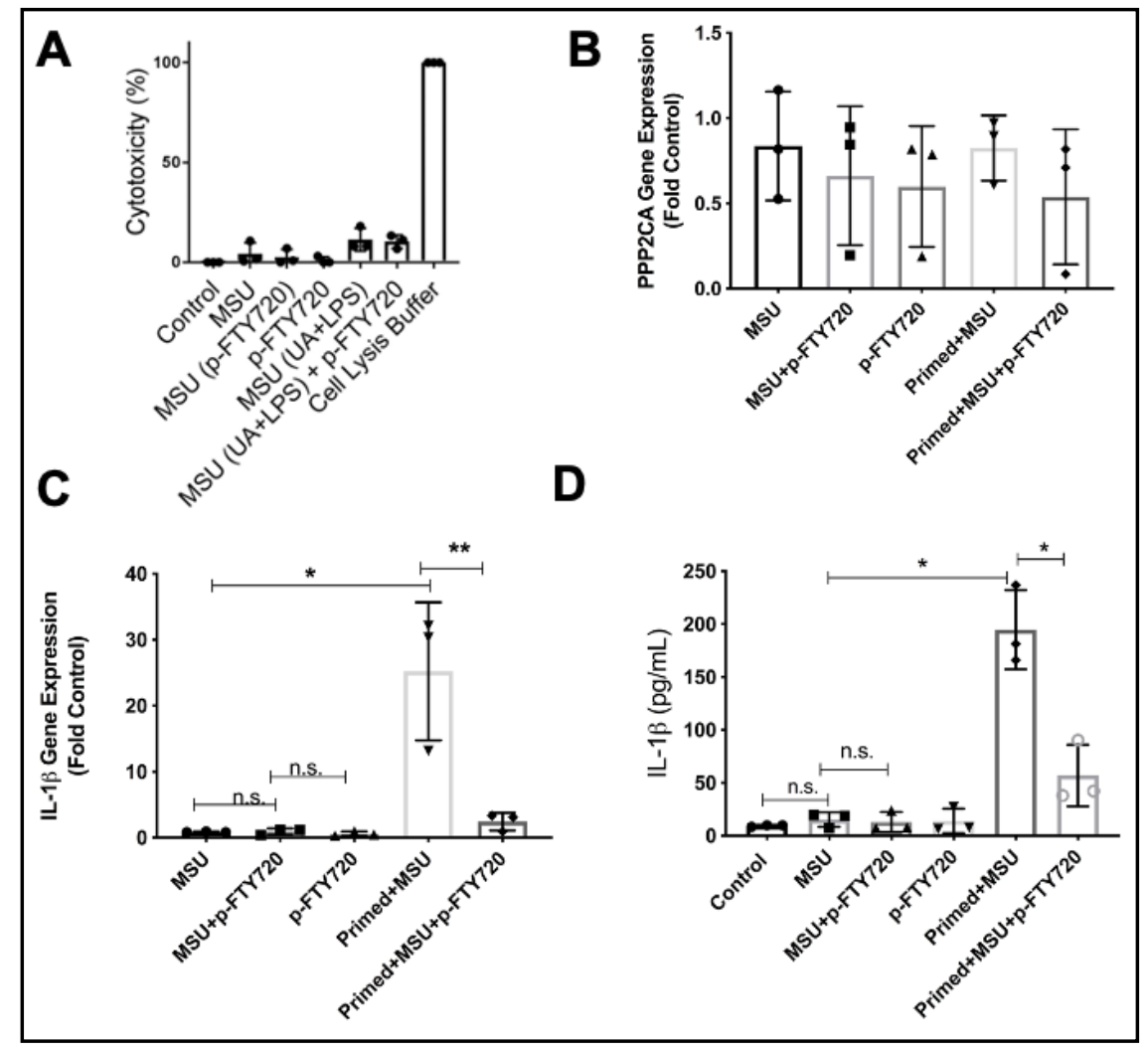

Figure 13 Impact of fingolimod phosphate (FTY720-P) treatment on THP-1 monocyte viability, expression of PP2Ac, IL-1 $\beta$ expression and production in UA + LPS primed and MSU stimulated monocytes. ${ }^{*} p<0.001$; ${ }^{* *} p<0.01$. A) FTY720-P treatment did not display significant cell toxicity. B) FTY720-P treatment did not alter PP2Ac gene expression. C) FTY720-P treatment reduced IL-1 $\beta$ gene expression. D) FTY720-P treatment reduced IL-1 $\beta$ production. 


\section{Discussion}

Gout is a chronic inflammatory disease which had been long associated with hyperuricemia (38). In hyperuricemia, MSU crystals are precipitated in articular joints, and are recognized by TLRs and subsequently activate the MyD88 NLRP3 pathway releasing caspase-1. Moreover, MSU crystals act on NF-kB pathway causing the transcription of the pro-inflammatory cytokine proIL- $1 \beta$ which is cleaved by caspase- 1 to IL- $1 \beta$ that is released from immune cells via exocytosis (39). LPS plays an important role in inflammation through its agonistic activity on TLR4 receptor stimulating the NLRP3 pathway (40). The role of hyperuricemia as an inflammatory signal had been controversial. A study had shown that uric acid has a dual role as anti-oxidant and pro-oxidant (41). On the other hand, other studies associated hyperuricemia with comorbidities involving oxidative stress suggesting that the inflammatory mechanism of hyperuricemia is caused by redox imbalance (42) or stimulation of TLR. Current available treatments for gout include colchicine, NSAIDs, corticosteroids and IL-1 $\beta$ receptor antagonists and despite their different modes of action, they all had serious adverse effects with no remarkable efficiency (43). Therefore, gout remains a research area of interest.

Protein phosphatase-2A (PP2A) is a heterotrimeric enzyme, which plays an important role in intracellular inflammatory pathways through its dephosphorylating key proteins in cell signaling cascades. Although it was studied intensively for its role in cancer as a potential therapeutic target (44), some emerging studies focused on its potential anti-inflammatory role via reducing the production of pro-inflammatory cytokines TNF-alpha and IL-6 following TLR4 agonistic activity by LPS (30). The activity of PP2A is regulated through the inhibitory enzyme SET 
which is bound to the catalytic subunit of PP2A preventing it from interacting with other intracellular components (45).

The most popular PP2A activating drug (PAD) is fingolimod (FTY720) which is present in two forms including: fingolimod hydrochloride prodrug (FTY720) and its active metabolite following intracellular phosphorylation by sphingosine kinase-2; fingolimod phosphate (FTY720-P). FTY720-P binds to SET releasing PP2A therefore rendering it active. Recent studies focused on FTY720-P's potential anti-inflammatory role by reducing release of IL-8 (35). In our study, we investigated the priming role of UA and LPS on THP-1 monocytes

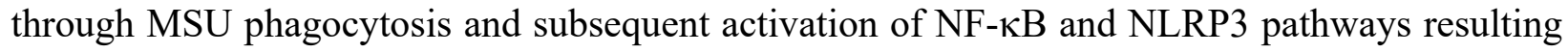
in expression and production of pro-inflammatory cytokine IL-1 $\beta$ and associating this with the reduction in PP2A activity. In addition, FTY720-P was used as a PAD to enhance PP2A activity and investigate whether PP2A activation produced an anti-inflammatory effect in our crystalinduced inflammation in vitro model.

We found that UA and LPS primed monocytes and enhanced phagocytosis of MSU crystals. Phagocytic activation of monocytes was confirmed using fluorescent FIT-C labeled latex beads. The priming of UA and LPS also enhanced phagocytosis of beads compared to control. However, unlike MSU crystals, higher bead phagocytosis was seen with LPS alone compared to UA alone. This could be due to the higher precipitation of MSU crystals with UA due to similar chemical composition, which didn't happen with the beads. In both cases, the dual activating effect of UA and LPS surpassed either of them alone. Priming corresponded with higher expression and production of the pro-inflammatory cytokine 
IL-1 $\beta$ following MSU phagocytosis. This could be due to the stimulation of NLRP3 and NF- $\kappa B$ pathways. Intracellular PP2A activity was not found to decrease with priming alone but after the phagocytosis of MSU crystals. This might be due to the dual signaling needed by the inflammatory pathway through both NLRP3 and NF-кB. The association of enhanced expression and production of IL-1 $\beta$ with a decrease in PP2A activity suggests that PP2A plays a role in in inflammation. The role of PP2A was further investigated by knocking down PP2Ac gene using PP2Ac siRNA. PP2A expression decreased with PP2A knockdown and this was associated with a decrease in PP2A activity. In unprimed monocytes after PP2A knockdown and MSU challenge, there was higher expression of IL-1 $\beta$ compared to control monocytes as well as enhanced IL-1 $\beta$ production. This confirms the previous association between the decrease of PP2A activity and increased severity of inflammation.

We further compared PP2A activation in THP-1 monocytes using the FTY720 prodrug and the active metabolite FTY720-P at different time points. The peak activity for FTY720 was observed at 6 hours while the peak activity for FTY720-P occurred at 1 hour. This is attributed to the metabolism of FTY720 since it takes about 6 hours to get uptaken into monocytes and phosphorylated by the intracellular sphingosine kinase-2 into FTY720-P, the active form of the drug. In case of FTY720-P, the addition of the active metabolite resulted in a quicker effect on PP2A activity. FTY720-P was therefore used as our PP2A activating drug in follow-up studies. In monocytes primed with UA and LPS, the decreased PP2A activity was reversed by the preincubation of cells with FTY720-P for 3 hours prior to MSU challenge affirming the PP2A restoring activity of FTY720 especially with primed monocytes. Furthermore, in primed monocytes, the higher expression and release of IL-1 $\beta$ was reversed by pre-incubation with 
FTY720-P. This confirms the anti-inflammatory role of FTY720-P through its action as a PP2A activating drug. Interestingly, PP2A activation was not due to an increased PP2A intracellular pool as FTY720-P treatment showed no significant effect on PP2A expression in primed cells compared to control. Finally, LDH cytotoxicity assay showed no significant cellular death confirming that all results aren't caused by cellular death due to priming or due to addition of FTY720-P.

\section{Conclusions}

We conclude that priming THP-1 monocytes using UA and LPS results in higher MSU phagocytosis and subsequently higher expression and production of IL-1 $\beta$ with decreased PP2A activity. Increasing PP2A activity through PADs as FTY720-P can reverse the pro-inflammatory effect of priming. PP2A is a novel target in gout. 


\section{References}

1. Tausche AK, Jansen TL, Schröder HE, Bornstein SR, Aringer M, Müller-Ladner U. Gout - Current Diagnosis and Treatment. Dtsch Arztebl. 2009;106(34-35):549-55.

2. Ragab G, Elshahaly M, Bardin T. Gout: An old disease in new perspective - A review. J Adv Res [Internet]. 2017;8(5):495-511. Available from:

http://dx.doi.org/10.1016/j.jare.2017.04.008

3. Kuo C-F, Grainge MJ, Zhang W, Doherty M. Global epidemiology of gout: prevalence, incidence and risk factors. Nat Rev Rheumatol [Internet]. 2015;11(11):649-62. Available from: https://doi.org/10.1038/nrrheum.2015.91

4. $\quad$ Ali S, Lally E V. Treatment failure gout. Med Health R I. 2009;92(11):369-71.

5. Cunha RN, Aguiar R, Farinha F, Ali S, Lally E V. Impact of pegloticase on patient outcomes in refractory gout: Current perspectives. Open Access Rheumatol Res Rev. 2009;10(11):141-9.

6. Bardin T, Richette P. Impact of comorbidities on gout and hyperuricaemia: An update on prevalence and treatment options. BMC Med. 2017;15(1):1-10.

7. Cronstein BN, Sunkureddi P. Mechanistic aspects of inflammation and clinical management of inflammation in acute gouty arthritis. J Clin Rheumatol. 2013;19(1):1929.

8. Wolff D. Gout. In: Enna SJ, Bylund DBBTTCPR, editors. New York: Elsevier; 2007. p. 1-8. Available from:

http://www.sciencedirect.com/science/article/pii/B9780080552323606816

9. Nuki G, Simkin PA. A concise history of gout and hyperuricemia and their treatment. Arthritis Res Ther. 2006;8(SUPPL. 1):1-5. 
10. Leung YY, Yao Hui LL, Kraus VB. Colchicine-Update on mechanisms of action and therapeutic uses. Semin Arthritis Rheum. 2015;45(3):341-50.

11. Singh JA, Saag KG. Management of gout. Ann Intern Med. 2017;166(11):855.

12. Kurowska-Stolarska M, Alivernini S. Synovial tissue macrophages: friend or foe? RMD Open. 2017;3(2):e000527.

13. Liu-Bryan R, Scott P, Sydlaske A, Rose DM, Terkeltaub R. Innate immunity conferred by Toll-like receptors 2 and 4 and myeloid differentiation factor 88 expression is pivotal to monosodium urate monohydrate crystal-induced inflammation. Arthritis Rheum. 2005;52(9):2936-46.

14. Gustafsson D, Unwin R. The pathophysiology of hyperuricaemia and its possible relationship to cardiovascular disease, morbidity and mortality. BMC Nephrol [Internet]. 2013;14(1):1. Available from: BMC Nephrology

15. Yang Y, Wang H, Kouadir M, Song H, Shi F. Recent advances in the mechanisms of NLRP3 inflammasome activation and its inhibitors. Cell Death Dis [Internet]. 2019;10(2). Available from: http://dx.doi.org/10.1038/s41419-019-1413-8

16. Kuwabara M. Hyperuricemia, Cardiovascular Disease, and Hypertension. Pulse. $2016 ; 3(3-4): 242-52$.

17. Mukherjee S, Karmakar S, Babu SPS. TLR2 and TLR4 mediated host immune responses in major infectious diseases: A review. Brazilian J Infect Dis [Internet]. 2016;20(2):193204. Available from: http://dx.doi.org/10.1016/j.bjid.2015.10.011

18. Li JY, Liu Y, Gao XX, Gao X, Cai H. TLR2 and TLR4 signaling pathways are required for recombinant Brucella abortus BCSP31-induced cytokine production, functional upregulation of mouse macrophages, and the Th1 immune response in vivo and in vitro. 
Cell Mol Immunol. 2014;11(5):477-94.

19. Pillinger MH, Igel TF, Krasnokutsky S. Recent advances in understanding and managing gout. F1000Research. 2017;6(0):1-11.

20. Qing Y-F, Zhang Q-B, Zhou J-G, Jiang L. Changes in toll-like receptor (TLR)4-NFкBIL1 $\beta$ signaling in male gout patients might be involved in the pathogenesis of primary gouty arthritis. Rheumatol Int [Internet]. 2014;34(2):213-20. Available from: https://doi.org/10.1007/s00296-013-2856-3

21. Acuner Ozbabacan SE, Gursoy A, Nussinov R, Keskin O. The Structural Pathway of Interleukin 1 (IL-1) Initiated Signaling Reveals Mechanisms of Oncogenic Mutations and SNPs in Inflammation and Cancer. PLoS Comput Biol. 2014;10(2).

22. Galliher-Beckley AJ. Caspase-1 activation and mature interleukin-1 $\beta$ release are uncoupled events in monocytes. World J Biol Chem. 2013;4(2):30.

23. Braga TT, Forni MF, Correa-Costa M, Ramos RN, Barbuto JA, Branco P, et al. Soluble Uric Acid Activates the NLRP3 Inflammasome. Sci Rep. 2017;7(November 2016):1-14.

24. Seshacharyulu P, Pandey P, Datta K, Batra SK. Phosphatase: PP2A structural importance, regulation and its aberrant expression in cancer. Cancer Lett. 2013;335(1):9-18.

25. Cohen PBT-M in E. [33] Classification of protein- serine/threonine phosphatases: identification and quantitation in cell extracts. In: Protein Phosphorylation Part B: Analysis of Protein Phosphorylation, Protein Kinase Inhibitors, and Protein Phosphatases [Internet]. Academic Press; 1991. p. 389-98. Available from: http://www.sciencedirect.com/science/article/pii/007668799101035Z

26. Gausdal G, Krakstad C, Herfindal L, Døskeland SO. Serine/threonine protein phosphatases in apoptosis. Apoptosis, Cell Signaling, Hum Dis. 2007;2:151-66. 
27. Alberts AS, Thorburnt AM, Shenolikart S, Mumby MC, Ii JRF. Retinoblastoma Phosphatases. Cell. 2000;90(January 1993):388-92.

28. Zhao H, Li D, Zhang B, Qi Y, Diao Y, Zhen Y, et al. PP2A as the main node of therapeutic strategies and resistance reversal in triple-negative breast cancer. Molecules. 2017;22(12):1-17.

29. Baskaran R, Velmurugan BK. Protein phosphatase 2A as therapeutic targets in various disease models. Life Sci [Internet]. 2018;210:40-6. Available from: http://www.sciencedirect.com/science/article/pii/S0024320518305241

30. Blatt NB, Dahmer MK, Shanley TP. Myeloid-specific gene deletion of Protein Phosphatase 2A (PP2A) magnifies MyD88- and TRIF-dependent inflammation following endotoxin challenge. 2018;198(1):404-16.

31. Manuscript A. Mechanism of Action of Oral Fingolimod in MS. Clin Neuropharmacol. 2010;33(2):91-101.

32. Sangodkar J, Farrington CC, McClinch K, Galsky MD, Kastrinsky DB, Narla G. All roads lead to PP2A: Exploiting the therapeutic potential of this phosphatase. FEBS J. 2016;283(6):1004-24.

33. Rahman MM, Prünte L, Lebender LF, Patel BS, Gelissen I, Hansbro PM, et al. The phosphorylated form of FTY720 activates PP2A, represses inflammation and is devoid of S1P agonism in A549 lung epithelial cells. Sci Rep [Internet]. 2016;6(May):6-13. Available from: http://dx.doi.org/10.1038/srep37297

34. Saddoughi SA, Gencer S, Peterson YK, Ward KE, Mukhopadhyay A, Oaks J, et al. Sphingosine analogue drug FTY720 targets I2PP2A/SET and mediates lung tumour suppression via activation of PP2A-RIPK1-dependent necroptosis. EMBO Mol Med. 
2013;5(1):105-21.

35. McHugh WM, Russell WW, Fleszar AJ, Rodenhouse PE, Rietberg SP, Sun L, et al.

Protein phosphatase $2 \mathrm{~A}$ activation attenuates inflammation in murine models of acute lung injury. Am J Physiol Lung Cell Mol Physiol [Internet]. 2016/09/16. 2016 Nov

1;311(5):L903-12. Available from: https://pubmed.ncbi.nlm.nih.gov/27638902

36. Crişan TO, Cleophas MCP, Novakovic B, Erler K, Van De Veerdonk FL, Stunnenberg $\mathrm{HG}$, et al. Uric acid priming in human monocytes is driven by the AKT-PRAS40 autophagy pathway. Proc Natl Acad Sci U S A. 2017;114(21):5485-90.

37. Livak KJ, Schmittgen TD. Analysis of Relative Gene Expression Data Using Real-Time Quantitative PCR and the 2- $\Delta \Delta \mathrm{CT}$ Method. Methods [Internet]. 2001;25(4):402-8. Available from: http://www.sciencedirect.com/science/article/pii/S1046202301912629

38. Pittman JR, Bross MH. Diagnosis and management of gout. Am Fam Physician. 1999;59(7):1799-806.

39. Orlowsky EW, Stabler T V., Montell E, Vergés J, Kraus VB. Monosodium urate crystal induced macrophage inflammation is attenuated by chondroitin sulphate: Pre-clinical model for gout prophylaxis? BMC Musculoskelet Disord. 2014;15(1).

40. Su Q, Li L, Sun Y, Yang H, Ye Z, Zhao J. Effects of the TLR4/Myd88/NF-кB Signaling Pathway on NLRP3 Inflammasome in Coronary Microembolization-Induced Myocardial Injury. Cell Physiol Biochem. 2018;47(4):1497-508.

41. Kang DH, Ha SK. Uric acid puzzle: Dual role as anti-oxidantand pro-oxidant. Electrolyte Blood Press. 2014;12(1):1-6.

42. Lu W, Xu Y, Shao X, Gao F, Li Y, Hu J, et al. Uric Acid Produces an Inflammatory Response through Activation of NF- $\mathrm{BB}$ in the Hypothalamus: Implications for the 
Pathogenesis of Metabolic Disorders. Sci Rep [Internet]. 2015;5(July):1-15. Available from: http://dx.doi.org/10.1038/srep12144

43. Cronstein BN, Terkeltaub R. The inflammatory process of gout and its treatment. Arthritis Res Ther [Internet]. 2006;8(1):S3. Available from: https://doi.org/10.1186/ar1908

44. Raman D, Pervaiz S. Redox inhibition of protein phosphatase PP2A: Potential implications in oncogenesis and its progression. Redox Biol [Internet]. 2019;27(October 2018):101105. Available from: https://doi.org/10.1016/j.redox.2019.101105

45. O’Connor CM, Perl A, Leonard D, Sangodkar J, Narla G. Therapeutic Targeting of PP2A. Int J Biochem Cell Biol. 2018;96:182-93. 